Special Article

\title{
THE COST EFFECTIVENESS OF STRATEGIES FOR THE TREATMENT OF INTESTINAL PARASITES IN IMMIGRANTS
}

Peter Muennig, M.D., M.P.H., Daniel Pallin, M.D., Randall L. Sell, Sc.D., and Man-Suen Chan, Ph.D.

\begin{abstract}
Background Currently, more than 600,000 immigrants enter the United States each year from countries where intestinal parasites are endemic. At entry persons with parasitic infections may be asymptomatic, and stool examinations are not a sensitive method of screening for parasitosis. Albendazole is a new, broad-spectrum antiparasitic drug, which was approved recently by the Food and Drug Administration. International trials have shown albendazole to be safe and effective in eradicating many parasites. In the United States there is now disagreement about whether to screen all immigrants for parasites, treat all immigrants presumptively, or do nothing unless they have symptoms.
\end{abstract}

Methods We compared the costs and benefits of no preventive intervention (watchful waiting) with those of universal screening or presumptive treatment with $400 \mathrm{mg}$ of albendazole per day for five days. Those at risk were defined as immigrants to the United States from Asia, the Middle East, subSaharan Africa, Eastern Europe, and Latin America and the Caribbean. Cost effectiveness was expressed both in terms of the cost of treatment per disabilityadjusted life-year (DALY) averted (one DALY is defined as the loss of one year of healthy life to disease) and in terms of the cost per hospitalization averted.

Results As compared with watchful waiting, presumptive treatment of all immigrants at risk for parasitosis would avert at least 870 DALYs, prevent at least 33 deaths and 374 hospitalizations, and save at least \$4.2 million per year. As compared with watchful waiting, screening would cost $\$ 159,236$ per DALY averted.

Conclusions Presumptive administration of albendazole to all immigrants at risk for parasitosis would save lives and money. Universal screening, with treatment of persons with positive stool examinations, would save lives but is less cost effective than presumptive treatment. (N Engl J Med 1999;340:773-9.) (C)1999, Massachusetts Medical Society.
I MMIGRATION to the United States has reached a historic high, with nearly 1 million citizens naturalized in 1996. ${ }^{1}$ Approximately 600,000 came from countries where intestinal parasites are endemic. Health policy with respect to managing parasitic disease varies within the United States and internationally. Governmental recommendations include universal screening, selective screening, and watchful waiting. ${ }^{2-4}$ Economic analyses of these approaches have been inconclusive. ${ }^{5,6}$

Presumptive treatment became a viable option in mid-1997, when the Food and Drug Administration approved albendazole, a broad-spectrum anthelmintic agent. ${ }^{7}$ This drug is inexpensive and is effective against Ascaris lumbricoides, Trichuris trichiura, hookworm (Ancylostoma duodenale and Necator americanus), Strongyloides stercoralis, Giardia lamblia, Opisthorchis viverrini, Taenia solium, and Hymenolepis nana. .14 $^{-14}$ Albendazole has been administered presumptively to thousands of persons living in areas of endemic disease and has caused no side effects requiring medical attention in field trials. ${ }^{8-13}$ Its safety has not been tested extensively in children under two years of age or in pregnant women.

Given the safety, efficacy, and low cost of albendazole, presumptive treatment of all immigrants to the United States has intuitive appeal. Nonetheless, because thousands of immigrants would have to be treated to prevent a few serious adverse events, a formal cost-effectiveness analysis is needed to guide public health policy. We undertook such an analysis.

The data base of the Healthcare Cost and Utilization Project 3 (HCUP-3) contains information on hospital charges and mortality for 20 percent of all hospital discharges nationwide. ${ }^{15}$ These data, however, do not permit geographic areas with large numbers of immigrants to be separated from those with

From the Refugee Health Program, New York City Department of Health (P.M.), the Preventive Medicine Residency Program, New York City Department of Health and Columbia University School of Public Health (P.M., D.P.), and the Division of Sociomedical Sciences, Columbia University School of Public Health (R.L.S.) - all in New York; and the Wellcome Trust Centre for the Epidemiology of Infectious Disease, University of Oxford, Oxford, United Kingdom (M.-S.C.). Address reprint requests to Dr. Muennig at the Refugee Health Program, New York City Department of Health, 125 Worth St., Box 21-A, New York, NY 10013. 
few immigrants. Moreover, cases of parasitosis acquired in areas of the United States where parasites are endemic are included in the data base. The data base of the New York Statewide Planning and Research Cooperative System (SPARCS) ${ }^{16}$ contains information that allows the probability of hospitalization for parasitic disease to be calculated for a nonendemic area with a large proportion of immigrants. Outpatient morbidity can be estimated on the basis of Medicaid reports from the Claim Detail/Special Reports (CD/SR) System of the New York State Department of Health's Office of Medicaid Management. ${ }^{17}$ We used data from these sources as the basis of our analyses.

In this report, outcomes are expressed in terms of disability-adjusted life-years (DALYs) averted. One DALY equals the loss of one healthy year of life to disease. One DALY averted is approximately equal to one quality-adjusted life-year gained. ${ }^{18}$ The DALY was chosen to facilitate comparisons with international studies.

\section{METHODS}

\section{Overview and Definitions}

Costs and outcomes were considered over the lifetime of the cohort, from the perspective of society as a whole. All future costs and DALYs were discounted at a rate of 3 percent. A cost-of-illness approach ${ }^{19}$ was used, and costs associated with secondary transmission and lost productivity were included. Our chief assumptions are listed in Table 1 . The models did not take into account the presence or absence of symptoms, because symptoms do not necessarily correlate with infection. ${ }^{24,25}$

The term "immigrants" in this study refers to documented and undocumented foreign entrants who plan to reside permanently in the United States; this group includes refugees and those seeking asylum. ${ }^{1}$ Immigrants at risk for parasitosis were defined as immigrants from one of the following five regions: Eastern Europe, Latin America and the Caribbean, sub-Saharan Africa, the Middle East, and Asia.

\section{Decision-Analysis Models}

A decision-analysis model was constructed with the use of DATA 3.0 software for the Macintosh computer (TreeAge Software, Williamstown, Mass.). The model examined three strategies: universal screening (with treatment of infected persons only), universal treatment, and no preventive intervention (watchful waiting). The variables used in the model are presented in Table 2.

Parasites included in the model were A. lumbricoides, Trich. trichiura, hookworm, and Strong. stercoralis. We excluded Schistosoma mansoni, O. viverrini, and $H$. nana because the SPARCS data predicted that the number of hospitalizations due to infections with these parasites would be negligible. ${ }^{15,16}$ Hospitalizations due to infections with Entamoeba histolytica and G. lamblia were excluded from the analysis because these organisms can be acquired in New York State, a fact that makes it difficult to determine whether the infection causing hospitalization was acquired domestically or abroad. Because Taen. solium, G. lamblia, O. viverrini, and $H$. nana are susceptible to albendazole, their exclusion caused the model to underestimate the benefits of presumptive treatment.

Each variable was tested for its influence on the results of the model in univariate and bivariate sensitivity analyses. The most plausible value for each variable was used to create a base-case result (Table 2). A best-case scenario was generated by assigning
Table 1. Principal Assumptions of the Analysis AND EvidenCe for AND Against Them.

Every case of parasitosis in the data base of the New York Statewide Planning and Research Cooperative System occurred in an immigrant.

None of the parasites in question is endemic in New York City.

It is unusual for travelers to contract the parasites we studied. ${ }^{20}$

More than one third of the population of New York City is foreignborn. ${ }^{21}$

Cases of parasitosis in war veterans and institutionalized persons were excluded from the analysis.

The entire cost of hospitalization for patients with a primary diagnosis of strongyloidiasis was attributable to strongyloidiasis.

The analysis included only hospitalizations for which Strongyloides stercoralis infection was recorded as the primary diagnosis. We assumed that such hospitalizations would not have occurred if there had been no Strong. stercoralis infection. We also ignored all costs associated with Strong. stercoralis infection as a nonprimary diagnosis.

No deaths were caused by infection with hookworm or Trichuris trichiura.

No deaths due to infections with these organisms were recorded in the Healthcare Cost and Utilization Project 3 data base. ${ }^{15}$

Treatment of Ascaris lumbricoides, hookworm, and Trich. trichiura infection with the prescribed regimen is 100 percent effective.

Studies show that 85 to 100 percent of organisms are eliminated with a single 400-mg dose of albendazole; the present protocol recommends five doses. 8,9

Even a partial reduction in the burden of parasites greatly reduces the chance of clinical sequelae because these parasites cannot reproduce in the host. ${ }^{22}$

Treatment of Strong. stercoralis infection with the prescribed regimen is 85 percent effective.

Clinical trials suggest that 85 percent of infected patients are cured with the recommended regimen. ${ }^{23}$

A partial reduction in the burden of parasites may not reduce the chance of clinical sequelae because Strong. stercoralis can reproduce in the host.

Compliance among immigrants is similar to compliance in the field trials used to establish the effectiveness of albendazole against strongyloidiasis. ${ }^{23}$

each variable the most extreme plausible value that would make presumptive treatment more cost effective. A worst-case scenario was created in a similar fashion.

\section{Sensitivity of the Stool Test and Prevalence of Parasites}

The sensitivity of the stool examination for ova and parasites varied according to the parasite. ${ }^{31,32}$ The prevalence of each parasite in the immigrant population was calculated from the known sensitivity of a single stool examination and the published rate of positive stool tests among immigrants to the United States. ${ }^{24,33-39}$

\section{Morbidity}

Data on hospitalizations were obtained from the New York City component of the SPARCS data base. ${ }^{16}$ The number of preventable future hospitalizations per year was estimated on the basis of the mean number of hospitalizations per year from 1990 through 1996. The New York City data were used because one third of the city's residents are immigrants, and because none of the parasites under study are endemic in the city.

The number of outpatient visits to health care providers was calculated on the basis of reports or Medicaid claims from the CD/SR System of the New York State Department of Health's Office of Medical Management. ${ }^{17}$ The number of preventable future outpatient visits per year was estimated on the basis of the mean number of outpatient visits per year from 1992 through 1996. Because the CD/SR System contains only data on Medicaid recipients, these data were adjusted to reflect all at-risk immigrants on the basis of the proportion of immigrants receiving Medicaid. ${ }^{40}$

In order to calculate the costs of future hospitalizations or out- 
Table 2. Selected Variables Used in the Decision-Analysis Model.

\begin{tabular}{|c|c|c|c|}
\hline VARIABLE & $\begin{array}{l}\text { BASE-CASE } \\
\text { VALUE }\end{array}$ & RANGE & COMMENTS \\
\hline \multicolumn{4}{|l|}{ Cost $(\$)^{*}$} \\
\hline Albendazole & 9 & $9-11$ & $\begin{array}{l}\text { Wholesale cost in U.S. plus a pharmacy fee of } \$ 0.25 \text { per } \\
\text { patient. }{ }^{26}\end{array}$ \\
\hline $\begin{array}{l}\text { Inpatient care } \\
\text { Ascaris lumbricoides } \\
\text { infection }\end{array}$ & 5,496 & $2,748-5,496$ & $\begin{array}{l}\text { Mean charge for an inpatient stay. }{ }^{15} \text { Low values are set } \\
\text { at half the base-case value. }\end{array}$ \\
\hline Hookworm infection & 4,733 & $2,367-4,733$ & \\
\hline $\begin{array}{l}\text { Trichuris trichiura } \\
\text { infection }\end{array}$ & 8,161 & $4,081-8,161$ & \\
\hline $\begin{array}{l}\text { Strongyloides stercoralis } \\
\text { infection }\end{array}$ & 31,940 & $15,970-31,940$ & \\
\hline \multicolumn{4}{|l|}{ Outpatient visit } \\
\hline Follow-up & 32 & $32-100$ & Cost of base Medicaid visit plus lost productivity. 27,28 \\
\hline $\begin{array}{l}\text { Strong. stercoralis } \\
\text { infection }\end{array}$ & 123 & $123-210$ & $\begin{array}{l}\text { Cost of Medicaid visit from the Claim Detail/Special } \\
\text { Reports System. }{ }^{17}\end{array}$ \\
\hline \multicolumn{4}{|l|}{ Stool examination } \\
\hline Positive & 67 & $67-150$ & $\begin{array}{l}\text { Cost of visit plus lost productivity plus cost of screening } \\
\text { test. }{ }^{27,28}\end{array}$ \\
\hline Negative & 35 & $24-55$ & Cost of screening test. ${ }^{28}$ \\
\hline \multicolumn{4}{|l|}{$\begin{array}{l}\text { Years of life lost per } \\
\text { death } \dagger\end{array}$} \\
\hline A. lumbricoides infection & 30 & - & Age at onset of disease was obtained from HCUP- $3 . .^{15}$ \\
\hline Strong. stercoralis infection & 22 & - & Age at onset of disease was obtained from HCUP- 3.15 \\
\hline \multicolumn{4}{|l|}{$\begin{array}{l}\text { Probability of medical } \\
\text { care and outcomes }\end{array}$} \\
\hline Outpatient visit & 0.0098 & $0.0041-0.0098$ & $\begin{array}{l}\text { The probability of an outpatient visit for } \\
\text { Strong. stercoralis. } .^{1721,29}\end{array}$ \\
\hline Hospitalization & 0.00197 & $0.0009-0.0048$ & $\begin{array}{l}\text { The probability of admission for Strong. stercoralis } \\
\text { infection. } .^{16,21,29}\end{array}$ \\
\hline Side effects & 0.01 & $0-0.05$ & $\begin{array}{l}\text { The assumed probability of a post-treatment medical } \\
\text { visit. }\end{array}$ \\
\hline Treatment & 0.85 & $0.6-1.0$ & $\begin{array}{l}\text { The probability that albendazole will eradicate } \\
\text { Strong. stercoralis. } .^{23}\end{array}$ \\
\hline \multicolumn{4}{|r|}{ - } \\
\hline Strong. stercoralis infection & 0.167 & $0.05-0.61$ & $\begin{array}{l}\text { The probability that the patient will die of disseminated } \\
\text { strongyloidiasis. } .^{15}\end{array}$ \\
\hline A. lumbricoides infection & 0.036 & $0.001-0.05$ & $\begin{array}{l}\text { The probability that the patient will die of } \\
\text { A. lumbricoides infection. }{ }^{30}\end{array}$ \\
\hline
\end{tabular}

${ }^{*}$ Costs have been rounded to the nearest dollar.

†Hookworm and Trich. trichiura infections were assumed to cause no deaths. HCUP-3 denotes Healthcare Cost and Utilization Project 3

patient visits in terms of present value, it was necessary to estimate the discounted probability of illness. This was defined as follows:

$$
P=\frac{N}{I} \times \sum_{1}^{t} \frac{1}{(1+r)^{t-1}},
$$

where $\mathrm{P}$ is the lifetime probability of illness due to a given parasite, $\mathrm{N}$ is the mean annual number of hospitalizations or outpatient visits in New York City, ${ }^{15-17} \mathrm{t}$ is the life expectancy of the parasite in years, I is the total number of infected immigrants residing in New York City, ${ }^{21,24,25,29,31-41}$ and $\mathrm{r}$ is the discount rate.

Whether infection with Strong. stercoralis resolves in a population over time has been a subject of debate. ${ }^{42}$ In the calculation of the rate of illness due to Strong. stercoralis, the value of I included all New York City immigrants infected with parasites, regardless of the year of immigration. ${ }^{21,29,41}$ This definition would result in an underestimate of $\mathrm{P}$ if the prevalence of parasitic infection decreased over time.

To predict the annual incidence of parasitic illness for all U.S. immigrants, we assumed that the same proportion of New York City immigrants would have these illnesses as of immigrants to the rest of the United States. This assumption was validated by a comparison of the predicted number of hospitalizations nationwide with the actual number as recorded in the HCUP-3 data base. ${ }^{15}$ The predicted number of hospitalizations due to $A$. lumbricoides, Trich. trichiura, and hookworm infections was equivalent to 84 percent of the hospitalizations recorded in HCUP-3..$^{15}$ For Strong. stercoralis infection, the model predicted 91.6 percent of the observed hospitalizations. ${ }^{15}$ Some of the difference may be accounted for by locally acquired parasitic infections reflected in the HCUP-3 data base; such infections were unlikely to occur in New York City.

\section{Mortality}

The mortality rate among patients hospitalized for Strong. stercoralis infection, according to the HCUP-3 data, was 16.7 percent. There were not enough cases listed in this data base for us to estimate mortality from any other parasite. De Silva et al. esti- 
mated mortality from $A$. lumbricoides infection to be approximately 5 percent among those hospitalized, on the basis of a weighted mean of case fatality rates in the international literature. ${ }^{30}$ One country for which data were used in devising this weighted mean, Brazil, had a mortality rate twice as high as the mean for the group of countries; it was considered an outlier and removed from the present analysis. This exclusion reduced the weighted mean mortality rate to 3.6 percent.

\section{Costs}

The wholesale costs of albendazole were obtained from MediSpan, a data base of wholesale drug costs. ${ }^{26}$ It was assumed that the cost of distribution of the medication would be $\$ 0.25$ per patient, resulting in a total cost of $\$ 8.81$ per patient for a regimen of $400 \mathrm{mg}$ per day for five days. Although albendazole caused no side effects requiring medical attention in field trials, ${ }^{8-14}$ it was assumed that 1 percent of all treated immigrants would require a follow-up visit.

The costs of lost productivity for all immigrant groups were estimated on the basis of data from the Office of Refugee Resettlement. ${ }^{27}$ The average length of the hospital stay for the treatment of each type of parasite was used to estimate lost wages due to hospitalization..$^{15}$ It was assumed that patients would require two working days for recovery after hospitalization and would lose two hours' worth of wages as a result of outpatient visits.

Mean hospital charges were derived from the HCUP-3 data. Medicaid reimbursement rates were used to estimate outpatient costs associated with parasitic illness and with medical visits for the evaluation of patients with positive stool samples and side ef- fects of medication. ${ }^{15,28}$ All costs were converted to 1997 dollars with use of the medical portion of the Consumer Price Index.

\section{DALYs}

DALYs averted were calculated according to the methods and disability weights cited in Murray and Lopez, ${ }^{43}$ with use of the Mathematica software package (Wolfram Research, Oxfordshire, United Kingdom). So as to ensure comparability with other North American cost-effectiveness studies, DALYs were not weighted for age.

\section{RESULTS}

\section{Costs Associated with Preventive Intervention}

The model predicted that at least 33 deaths, 374 hospitalizations, and $\$ 4.2$ million in costs would be averted annually if all 1996 immigrants from the five regions received presumptive treatment rather than no preventive intervention (Table 3 ). When applied separately to each of the regions considered, the model predicted that presumptive treatment would save costs for immigrants from all regions but the Middle East, where the incremental cost would equal $\$ 4,630$ per DALY averted or $\$ 5,029$ per hospitalization averted. The model predicted that screening would avert fewer DALYs than presumptive treat-

Table 3. Cost Effectiveness of Presumptive Treatment and Selective Screening, as Compared with no Preventive Intervention.*

\begin{tabular}{|c|c|c|c|c|c|c|}
\hline \multirow{2}{*}{ VARIABLE } & \multicolumn{5}{|c|}{ REGION OF URIGIN } & \multirow[t]{2}{*}{ IOTAL } \\
\hline & AsIA & $\begin{array}{l}\text { MIDDLE } \\
\text { EAST }\end{array}$ & $\begin{array}{c}\text { SUB- } \\
\text { SAHARAN } \\
\text { AFRICA }\end{array}$ & $\begin{array}{c}\text { LATIN } \\
\text { AMERICA AND } \\
\text { THE CARIBBEAN }\end{array}$ & $\begin{array}{l}\text { EASTERN } \\
\text { EUROPE }\end{array}$ & \\
\hline No. of immigrants in 1996 & 282,632 & 5,047 & 51,537 & 267,334 & 91,972 & 698,522 \\
\hline \multicolumn{7}{|l|}{ No preventive intervention } \\
\hline $\begin{array}{l}\text { Gross cost (\$) } \\
\text { Hospitalizations (no.) }\end{array}$ & $\begin{array}{r}6,330,957 \\
228\end{array}$ & $\begin{array}{r}40,073 \\
1\end{array}$ & $\begin{array}{r}1,154,429 \\
33\end{array}$ & $\begin{array}{r}2,649,280 \\
94\end{array}$ & $\begin{array}{r}911,443 \\
18\end{array}$ & $\begin{array}{r}11,086,181 \\
374\end{array}$ \\
\hline \multicolumn{7}{|l|}{ Treatment with albendazole } \\
\hline $\begin{array}{l}\text { Gross cost }(\$) \\
\text { Net cost }(\$) \dagger \\
\text { Lives saved (no.) } \\
\text { DALYs averted (no.) } \\
\text { Cost/DALY averted (\$)‡ } \\
\text { Cost/hospitalization } \\
\text { averted }(\$) \ddagger\end{array}$ & $\begin{array}{r}3,227,657 \\
-3,103,299 \\
21 \\
-\quad 543 \\
-\end{array}$ & $\begin{array}{r}46,634 \\
6,561 \\
0 \\
1 \\
4,630 \\
5,029\end{array}$ & $\begin{array}{r}588,553 \\
-565,876 \\
4 \\
-\quad 94 \\
-\quad\end{array}$ & $\begin{array}{r}2,550,366 \\
-548,035 \\
7 \\
-191 \\
-\quad\end{array}$ & $\begin{array}{r}877,413 \\
-34,030 \\
2 \\
-\quad 40 \\
-\end{array}$ & $\begin{array}{r}7,290,624 \\
-4,244,679 \\
33 \\
-\quad 870 \\
-\quad\end{array}$ \\
\hline \multicolumn{7}{|l|}{ Screening } \\
\hline $\begin{array}{l}\text { Gross cost }(\$) \\
\text { Net cost }(\$) \\
\text { Incremental cost }(\$) \$\end{array}$ & $\begin{array}{l}18,077,143 \\
11,746,186 \\
14,849,485\end{array}$ & $\begin{array}{l}256,741 \\
216,668 \\
210,107\end{array}$ & $\begin{array}{l}3,296,307 \\
2,141,878 \\
2,707,754\end{array}$ & $\begin{array}{l}14,075,135 \\
11,425,855 \\
11,973,890\end{array}$ & $\begin{array}{l}4,842,326 \\
3,930,883 \\
3,964,913\end{array}$ & $\begin{array}{l}40,547,651 \\
29,461,470 \\
33,706,149\end{array}$ \\
\hline $\begin{array}{l}\text { Incremental cost }(\$) \mathbb{S} \\
\text { Lives saved (no.) }\end{array}$ & $\begin{array}{r}14,849,485 \\
7\end{array}$ & $\begin{array}{r}210,107 \\
0\end{array}$ & $\begin{array}{r}2, / 0 /, 74 \\
1\end{array}$ & 3 & 1 & $\begin{array}{r}50,700,149 \\
12\end{array}$ \\
\hline DALYs averted (no.) & 115 & 0 & 20 & 41 & 9 & 185 \\
\hline Cost/DALY averted (\$) & 101,801 & 722,372 & 106,706 & 280,966 & 457,383 & 159,236 \\
\hline $\begin{array}{l}\text { Cost/hospitalization } \\
\text { averted (\$) }\end{array}$ & 56,491 & 169,981 & 73,597 & 131,011 & 229,915 & 85,989 \\
\hline
\end{tabular}

*DALY denotes disability-adjusted life-year. Because all figures have been rounded to the nearest whole number, it may not be possible to reproduce exact calculations. Costs and DALYs have been discounted at 3 percent.

†A negative number indicates a cost savings.

$\ddagger$ Cost savings were realized for all regions except the Middle East. No values are shown for other regions, because costeffectiveness ratios cannot be calculated for cost-saving interventions.

\$Costs shown are the amounts by which the costs with screening exceed those with presumptive treatment. 


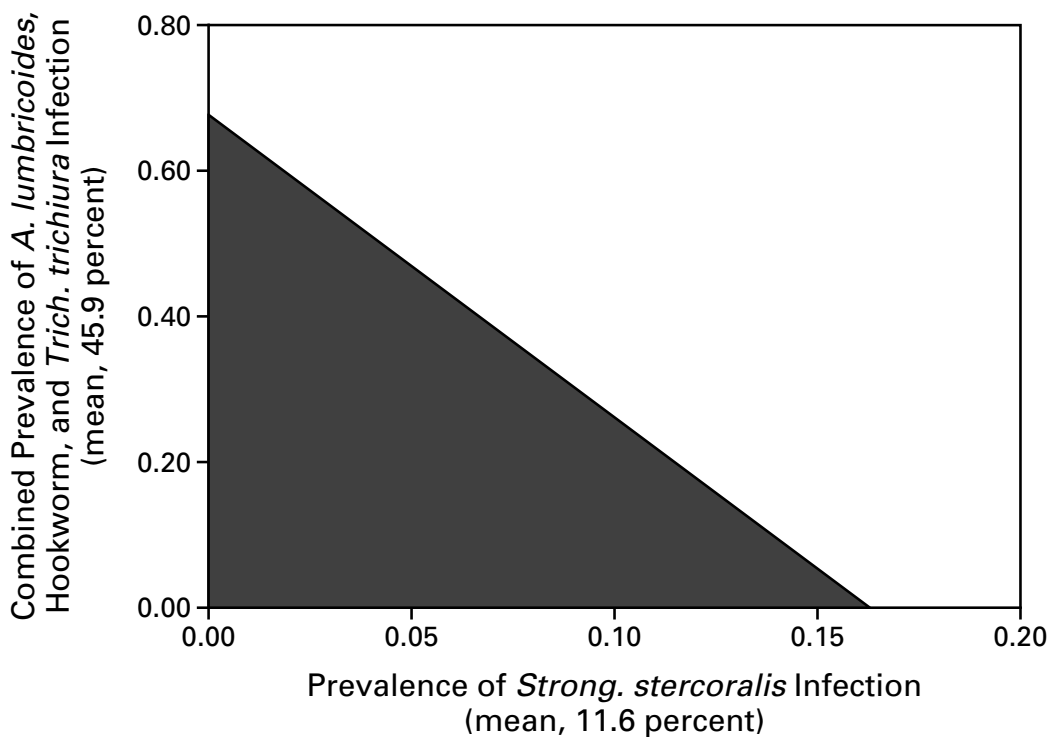

Figure 1. Two-Way Sensitivity Analysis.

The intersection of the prevalence of Strongyloides stercoralis infection with the sum of the prevalence rates for Ascaris lumbricoides, hookworm, and Trichuris trichiura infections indicates whether presumptive treatment costs more than watchful waiting (solid area) or saves money (open area). Means for prevalence values are weighted means for all geographic regions combined.

ment in all regions; it also predicted that screening would cost $\$ 159,236$ per DALY averted and $\$ 85,989$ per hospitalization averted, as compared with watchful waiting.

\section{Sensitivity Analyses}

The outcome of each strategy was most sensitive to changes in the following variables, in descending order of sensitivity: the prevalence of Strong. stercoralis infection, the probability that treatment will be successful, the probability that the medication produces side effects, the probability of hospitalization due to Strong. stercoralis, and the cost of hospitalization.

In a bivariate sensitivity analysis, the mean prevalence of Strong. stercoralis was varied between zero and the highest values obtained from the medical literature (Fig. 1). The threshold value for cost savings was tested for each variable to which the model was sensitive (Table 4). The outcome was qualitatively unchanged (i.e., presumptive treatment resulted in cost savings as compared with watchful waiting) for all plausible values used for all variables tested. Presumptive treatment also saved money when we used discount rates ranging from 0 percent (1439 DALYs averted and $\$ 8.6$ million saved) to 5 percent (32 DALYs averted and $\$ 2.7$ million saved).

In the best-case scenario, presumptive treatment would save \$16.4 million while preventing 1976 DALYs and averting 700 hospitalizations, as compared with watchful waiting. In the worst-case sce-

\begin{tabular}{|c|c|c|}
\hline VARIABLE & $\begin{array}{l}\text { THRESHOLD } \\
\text { RATE } \\
(\%)\end{array}$ & EXPLANATION \\
\hline $\begin{array}{l}\text { Successful treatment } \\
\text { of Strongyloides } \\
\text { stercoralis infection }\end{array}$ & 29 & $\begin{array}{l}\text { Cost savings would be realized so long } \\
\text { as the efficacy of treatment was } \\
\text { greater than } 29 \text { percent. }\end{array}$ \\
\hline Side effects & 20 & $\begin{array}{l}\text { Cost savings would be realized so long } \\
\text { as albendazole produced side effects } \\
\text { requiring a follow-up visit in fewer } \\
\text { than } 20 \text { percent of the treated } \\
\text { immigrants. }\end{array}$ \\
\hline $\begin{array}{l}\text { Hospitalization for } \\
\text { Strong. stercoralis } \\
\text { infection }\end{array}$ & 34 & $\begin{array}{l}\text { Cost savings would be realized so long } \\
\text { as the actual probability of hospital- } \\
\text { ization for Strong. stercoralis infec- } \\
\text { tion was not less than } 34 \text { percent of } \\
\text { the predicted value. }\end{array}$ \\
\hline Real value of charges & 69 & $\begin{array}{l}\text { Cost savings would be realized overall } \\
\text { so long as society's actual costs were } \\
\text { not lower than } 69 \text { percent of the } \\
\text { charges reported by hospitals. }\end{array}$ \\
\hline
\end{tabular}

nario, presumptive treatment would cost $\$ 25,644$ per DALY averted and $\$ 16,481$ per hospitalization averted, also as compared with watchful waiting.

\section{DISCUSSION}

If all immigrants to the United States in 1996 who were at risk for intestinal parasitosis had been given a five-day course of albendazole $(400 \mathrm{mg}$ orally per day), 33 lives would have been saved, 374 
hospitalizations would have been averted, and 870 DALYs would have been averted. Holding prevalence constant, the best-case scenario predicted a cost savings of $\$ 16.4$ million and prevention of 1976 DALYs, and the worst-case scenario predicted a cost of $\$ 25,644$ per DALY averted.

Outcomes differed among the regions of origin of immigrants according to the prevalence of parasites. For an immigrant group with a known prevalence, Figure 1 can be used to determine whether or not presumptive treatment would save costs.

The exclusion of parasites susceptible to albendazole and the use of conservative assumptions about the probability of illness due to Strong. stercoralis decreased the predicted cost savings associated with the substitution of presumptive treatment for watchful waiting. Despite the fact that the model was conservative with respect to the benefits of presumptive treatment, savings were still predicted. This increases the likelihood that cost savings would result if perfect data were available.

The decision-analysis model was robust when changes were made in all variables over the range of their plausible values, and cost savings with presumptive treatment persisted in all univariate sensitivity analyses. Even in the worst-case scenario, the cost-effectiveness ratio for presumptive treatment of parasites compares favorably with that for the prevention of opportunistic infections in patients with the acquired immunodeficiency syndrome. ${ }^{4}$ The mathematical model used to calculate morbidity due to parasites underestimated the total number of cases recorded in the HCUP-3 data base. Because some of the hospitals included in this data base were located in areas where the parasites we studied were endemic, it is likely that the model predicts the prevalence of illness in immigrant populations more accurately than would the HCUP-3 data base.

Strong. stercoralis infection was responsible for most of the deaths and hospital costs in this study. This organism typically causes severe illness in patients receiving immunosuppressive therapy. ${ }^{45} \mathrm{We}$ assumed that the costs of hospitalization for the underlying illnesses leading to immunosuppressive therapy would not have been incurred had the patient been uninfected; however, clinical strongyloidiasis may have developed in some patients during prolonged hospital stays for other illnesses. The effect of this assumption on costs is offset by the conservative assumptions used to determine the probability of illness due to the organism. Furthermore, only patients with a primary diagnosis of strongyloidiasis were included in the analysis.

Mortality due to Strong. stercoralis infection almost invariably results from the hyperinfection syndrome, which is fatal in 61 percent of cases in hospitalized persons. ${ }^{45}$ Among uninfected patients with conditions that commonly predispose patients to the hyperinfection syndrome, less than 0.1 percent of those in the SPARCS data base died while in the hospital, whereas 16.7 percent of hospitalized patients with a primary diagnosis of massive strongyloidiasis died. ${ }^{16,45}$

Another limitation of the study is that E. histolytica was not included in the decision-analysis model because it is present in untreated water sources in New York State. Inclusion of this parasite might have decreased the marginal cost of screening as compared with watchful waiting, but it would have had no effect on the cost of treatment as compared with watchful waiting. Finally, the true savings to society may have been underrepresented because it was necessary to exclude Taen. solium, G. lamblia, O. viverrini, and $H$. nana infections, which are susceptible to albendazole therapy.

In rare instances, O. viverrini causes cholangiocarcinoma, a fatal cancer that may be prevented by the treatment regimen we studied in infected persons who have not yet undergone malignant changes. ${ }^{11,46}$ Neurocysticercosis is the most common inpatient disorder due to parasitic infection..$^{15}$ Public health benefits may be realized from eradicating Taen. soli$u m$ by means of mass treatment. ${ }^{47,48}$ There is a hypothetical risk of seizure or blindness associated with the treatment of occult neurocysticercosis, but no side effects requiring medical attention have occurred in thousands of patients in areas where the disease is endemic who have received albendazole at doses similar to those used in this study. ${ }^{8-14}$ Clinicians may wish to inquire about the presence of headaches or seizures before initiating presumptive treatment, and they should not consider treatment a substitute for other preventive or diagnostic tests, such as liverenzyme studies.

The cost of albendazole treatment in this analysis was $\$ 8.56$ (exclusive of the distribution charge), because this was the prevailing wholesale price in the United States in 1997, but government purchasers in the United States would pay less. This regimen can be purchased for as little as $\$ 0.71$ in other countries. Ivermectin, an alternative drug for presumptive treatment that is more effective against Strong. stercoralis than albendazole, was not analyzed because of its high cost $(\$ 19.30)^{26}$ and its narrow spectrum of coverage. ${ }^{12}$

Cost savings resulting from medical interventions are rare. Precedents for such cost savings include targeted vaccination and contraceptive use by adolescents. ${ }^{49,50}$ Though the treatment strategy we studied did not reduce medical costs for immigrants from the Middle East - because of the low prevalence of parasites in that population - the cost per DALY averted was similar to the costs associated with smoking cessation according to guidelines of the Agency for Health Care Policy and Research. ${ }^{51}$ The costs per DALY averted for screening of Asian and 
sub-Saharan African immigrants were similar to those associated with vaccination against hepatitis $\mathrm{A}$ in health care workers..$^{52}$

We are indebted to Marcelle Layton, M.D., Susan Cookson, M.D., and Martin Cetron, M.D., for their help with the design of the costeffectiveness analysis and with editing of the manuscript and to Burt Roberts, M.P.A., for assistance with the preparation of the manuscript.

\section{REFERENCES}

1. Statistical yearbook of the immigration and naturalization service, 1996 . Washington, D.C.: Immigration and Naturalization Service, 1997.

2. Keystone JS. Imported intestinal parasites: a growing problem? Can Med Assoc J 1981;125:415-6, 450.

3. Persson A, Rombo L. Intestinal parasites in refugees and asylum seeker entering the Stockholm area, 1987-88: evaluation of routine stool screening. Scand J Infect Dis 1994;26:199-207.

4. Gyorkos TW, Frappier-Davignon LF, MacLean JD, Viens P. Effect of screening and treatment on imported intestinal parasite infections: results from a randomized, controlled trial. Am J Epidemiol 1989;129:75361.

5. Barrett-Connor E. Direct dollar costs and savings of screening stool examinations for eggs and parasites in adult Southeast Asian refugees. Am J Trop Med Hyg 1982;31:466-8.

6. Anderson JP, Moser RJ. Parasite screening and treatment among Indochinese refugees: cost-benefit/utility and the General Health Policy Model. JAMA 1985;15:2229-35.

7. Albenza. Philadelphia: SmithKline Beecham Pharmaceuticals, 1997 (package insert)

8. Albonico M, Smith PG, Hall A, Chwaya HM, Alawi KS, Savioli L. A randomized controlled trial comparing mebendazole and albendazole against Ascaris, Trichuris and hookworm infections. Trans R Soc Trop Med Hyg 1994;88:585-9.

9. Rossignol JF, Maisonneuve H. Albendazole: placebo-controlled study in 870 patients with intestinal helminthiasis. Trans R Soc Trop Med Hyg 1983;77:707-11

10. Romero-Cabello R, Robert L, Muñoz-Garcia R, Tanaka J. Estudio aleatorio para comparar seguridad y eficacia de albendazol y metronidazol en el tratamiento de giardiasis en niños. Rev Latinoam Microbiol 1995;37: 315-23.

11. Pungpak S, Bunnag D, Harinasuta T. Albendazole in the treatment of opisthorchiasis and concomitant intestinal helminthic infections. Southeast Asian J Trop Med Public Health 1984;15:44-50.

12. Marti H, Haji HJ, Savioli L, et al. A comparative trial of a single-dose ivermectin versus three days of albendazole for treatment of Strongyloides stercoralis and other soil-transmitted helminth infections in children. Am J Trop Med Hvg 1996;55:477-81.

13. Hall A, Nahar Q. Albendazole as a treatment for infections with Giardia duodenalis in children in Bangladesh. Trans R Soc Trop Med Hyg 1993;87:84-6

14. Archibald LK, Beeching NJ, Gill GV, Bailey JW, Bell DR. Albendazole is effective treatment for chronic strongyloidiasis. QJM 1993;86:191 5 .

15. Healthcare Cost and Utilization Project 3 (HCUP-3). Rockville, Md. Agency for Health Care Policy and Research, 1994 (software).

16. Statewide Planning and Research Cooperative System (SPARCS). Albany: New York State Department of Health, 1996 (software)

17. Claim Detail/Special Reports (CD/SR) System. Albany: New York State Department of Health, Office of Medicaid Management, 1996 (software).

18. Murray CLJ, Lopez AD, eds. The global burden of disease: a comprehensive assessment of mortality and disability from disease, injuries, and risk factors in 1990 and projected to 2020. Vol. 1. Cambridge, Mass.: Harvard School of Public Health, 1996:64-7.

19. Gold MR, Siegel JE, Russell LB, Weinstein MC, eds Cost-effectiveness in health and medicine. New York: Oxford University Press, 1996.

20. Gilles HM, Ball PAJ, eds. Human parasitic diseases. Vol. 4. Amsterdam: Elsevier, 1991:170.

21. Bureau of the Census. 1990 Census of the population: social and economic characteristics, New York. Vol. 1. Section 1. Washington, D.C.: Department of Commerce, 1993:CP-2-3 (table 168).

22. Guyatt HL, Bundy DA. Estimating prevalence of community morbidity due to intestinal helminths: prevalence of infection as an indicator of the prevalence of disease. Trans R Soc Trop Med Hyg 1991;85:778-82.
23. Grove DI, ed. Strongyloidiasis: a major roundworm infection of man. New York: Taylor and Francis, 1989:218.

24. Salas SD, Heifetz R, Barrett-Connor E. Intestinal parasites in Central American immigrants in the United States. Arch Intern Med 1990;150: 1514-6.

25. Buchwald D, Lam M, Hooton TM. Prevalence of intestinal parasites and association with symptoms in Southeast Asian refugees. J Clin Pharm Ther 1995;20:271-5.

26. Medi-Span. Indianapolis: Hearst Data, 1997 (software).

27. Office of Refugee Resettlement. Refugee resettlement program report to the Congress FY 1995. Hyattsville, Md.: Department of Health and Human Services, 1995.

28. MMIS provider manual: Medicaid management information system. Albany: New York State Department of Social Services, 1997.

29. The newest New Yorkers 1990-1994: an analysis of immigration to NYC in the early 1990s. New York: New York City Department of City Planning, 1996:7-8. (Publication no. DCP 96-19.)

30. de Silva NR, Chan MS, Bundy DA. Morbidity and mortality due to ascariasis: re-estimation and sensitivity analysis of global numbers at risk. Trop Med Int Health 1997;2:519-28.

31. Marti $\mathrm{H}$, Koella JC. Multiple stool examinations for ova and parasites and rate of false-negative results. J Clin Microbiol 1993;31:3044-5.

32. Sato Y, Kobayashi J, Toma H, Shiroma Y. Efficacy of stool examination for detection of Strongyloides infection. Am J Trop Med Hyg 1995;53: 248-50.

33. Refugee Health Program dataset. Minneapolis: Minnesota Department of Health Refugee Health Program, 1997 (software).

34. Refugee Health Program dataset. Jamaica Plain: Massachusetts Department of Health Refugee and Immigrant Health Program, 1997 (software).

35. Genta RM. Global prevalence of strongyloidiasis: critical review with epidemiologic insights into the prevention of disseminated disease. Rev Infect Dis 1989;11:755-67.

36. McCaw BR, DeLay P. Demographics and disease prevalence of two new refugee groups in San Francisco: the Ethiopian and Afghan refugees. West J Med 1985;143:271-5.

37. Arfaa F. Intestinal parasites among Indochinese refugees and Mexican immigrants resettled in Contra Costa County, California. J Fam Pract $1981 ; 12: 223-6$

38. Catanzaro A, Moser RJ. Health status of refugees from Vietnam, Laos, and Cambodia. JAMA 1982;247:1303-8

39. Skeels MR, Nims LJ, Mann JM. Intestinal parasitosis among Southeast Asian immigrants in New Mexico. Am J Public Health 1982;72:57-9.

40. Bureau of the Census. 1996 Current population survey. Washington, D.C.: Department of Commerce, 1996 (software).

41. Fernandez EW, Robinson JG. Illustrative ranges of the distribution of undocumented immigrants by state. Bureau of the Census technical working paper no. 8. Washington, D.C.: Bureau of the Census, 1994.

42. Gill GV, Bell DR. Strongyloides stercoralis infection in former Far East prisoners of war. BMJ 1979;2:572-4

43. Murray CLJ, Lopez AD. The global burden of disease: a comprehensive assessment of mortality and disability from disease, injuries, and risk factors in 1990 and projected to 2020. Vol. 1. Cambridge, Mass.: Harvard School of Public Health, 1996:413.

44. Freedberg KA, Scharfstein JA, Seage GR III, et al. The cost-effectiveness of preventing AIDS-related opportunistic infections. JAMA 1998; 279:130-6.

45. Grove DI, ed. Strongyloidiasis: a major roundworm infection of man. New York: Taylor and Francis, 1989:210-1

46. Pungpak S, Viravan C, Radomyos B, et al. Opisthorchis viverrini infection in Thailand: studies on the morbidity of the infection and resolution following praziquantel treatment. Am J Trop Med Hyg 1997;56:3114 .

47. Allan JC, Velasquez-Tohom $M$, Fletes $C$, et al. Mass chemotherapy for intestinal Taenia solium infection: effect on prevalence in humans and pigs. Trans R Soc Trop Med Hyg 1997;91:595-8.

48. Schantz PM, Moore AC, Muñoz JL, et al. Neurocysticercosis in an Orthodox Jewish community in New York City. N Engl J Med 1992;327: $692-5$.

49. Sisk JE, Moskowitz AJ, Whang W, et al. Cost-effectiveness of vaccination against pneumococcal bacteremia among elderly people. JAMA 1997; 278:1333-9

50. Trussell J, Koenig J, Stewart F, Darroch JE. Medical care cost savings from adolescent contraceptive use. Fam Plann Perspect 1997;29:248-55, 295 51. Cromwell J, Bartosch WJ, Fiore MC, Hasselblad V, Baker T. Costeffectiveness of the clinical practice recommendations in the AHCPR guideline for smoking cessation. JAMA 1997;278:1759-66.

52. Smith S, Weber S, Wiblin T, Nettleman M. Cost-effectiveness of hepatitis A vaccination in healthcare workers. Infect Control Hosp Epidemiol 1997;18:688-91. 